\title{
Evaluation of TRMM satellite rainfall in driving Variable Infiltration Capacity (VIC) model in Ganjiang Basin
}

\author{
Yuhan Huang ${ }^{1, a}$, Zengxin Zhang ${ }^{1, b, *}$, Qiu Jin ${ }^{1, c}$ \\ ${ }^{1} J o i n t$ Innovation Center for Modern Forestry Studies, College of Biology and the Environment, \\ Nanjing Forestry University, Nanjing, Jiangsu, China, 210037 \\ aecoyuhan@163.com, bnfuzhang@163.com, ananjqiu@163.com
}

Keywords: Hydrology, TMPA, remote sensing, satellite.

Abstract. Global rainfall data is very important for water resource research. Current rainfall data are mainly from the rain gauge on the ground, ground radar and space borne passive radiometer. This study assesses the successive Version-6 and Version-7 TRMM Multi-satellite Precipitation Analysis (TMPA) products (3B42V6, 3B42V7, 3B42RTV6 and 3B42RTV7) in Ganjiang River Basin, southeastern China. The results shows that compared with ground observed precipitation, the TMPA rainfall estimates are well captured by 3B42V6, 3B42V7 and 3B42RTV7. In terms of daily grid-based comparison, 3B42RTV7 has been improved over 3B42RTV6 by reducing relative bias from $-24,15 \%$ to $12.05 \%$, and the root-mean-square error (RMSE) improves from $5.98 \mathrm{~mm}$ to $5.69 \mathrm{~mm}$. Using these TMPA products as input to simulate daily hydrologic with VIC hydrologic model shows that: 1) 3B42V6 and 3B42V7 show very comparable hydrologic skills, with high Nash-Sutcliffe index (NSCE, 0.72 and 0.75 , respectively) and strong correlation $(\mathrm{CC}=0.89)$; 2) 3B42RTV7 shows display a better hydrologic performance over 3B42RTV6 by increasing the NSCE from 0.55 to 0.58 , improving CC from 0.81 to 0.86 , and reducing relative bias from $-34.28 \%$ to $15.71 \%$.

\section{Introduction}

Recently, high-resolution satellite precipitation products have witnessed significant development. These growing availability products have significant importance in applications such as climate change, natural hazards, and hydrological simulation and water resource management[1]. Hydrologists have tremendous opportunities to improve hydrological process simulation and flood prediction capacity in various kinds of river basins by using large-scale distributed hydrological models, especially in no observation data area and remote regions. The rainfall is one of the most important inputs for hydrological models, and a hydrological model's stream flow predictions is heavily dependent on the accuracy of rainfall inputs. Therefore, it is a great concern that the rainfall patterns over a basin and a region is accurate estimate.

In recent years, numbers of global high resolution satellite-based precipitation products have been operationally available. Those products have provided global high-temporal $(\leqslant 3 \mathrm{~h})$ and spatial $(\leqslant$ $0.25^{\circ}$ ) resolution precipitation maps. The Tropical Rainfall Measuring Mission (TRMM) is the most popular product, which measuring precipitation over the oceans and tropics. Several recent studies have reported on the improvement of the Version-7 TMPA over earlier Version-6. Chen[2] compared the daily mean precipitation of $3 \mathrm{~B} 42 \mathrm{~V} 6$ to $3 \mathrm{~B} 42 \mathrm{~V} 7$ over China and found that the correlation coefficient (CC) increases from 0.89 to 0.93 , the relative bias (RB) improves from $-4.91 \%$ to $-0.05 \%$, and the root-mean-square error (RMSE) improves from $0.69 \mathrm{~mm}$ to $0.54 \mathrm{~mm}$. Yong's[3] assessments indicat that RTV7 represents a substantial improvement over RTV6 in the low-latitude Mishui basin, and Version-7 algorithm notably reduces the bias between TMPA and observations during winter months. In Liu's[4] research, for light rain, V6 estimate less rainfall than V7 over land and oceans; rainfall estimates in V6 are larger than those in V7 over land in most years in moderate rain regimes; for heavy rain, rainfall estimates in V6 are larger than those in V7 throughout in both land and oceans. Prakash[5] found that in west coast, northeastern, and central India, biases are improved by 5\%-10\% in V7 over typical monsoon rainfall zones. 
Poyang Lake is the largest fresh water lake in China, Ganjiang River is the main tributary of Poyang Lake, and has a great impact on Poyang Lake. This paper aims to get quantitative how much previous TMPA V7 improve than TMPA V6 and the two versions of TMPA products shows in the streamflow hydrographs.

The major objectives of the study are to (1) Find out the spatiotemporal error characteristics of four standard TMPA (3B42RTV6, 3B42RTV7, 3B42V6 and 3B42V7) and quantitative analysis their difference and (2) using the TMPA products data in VIC model, to further analyze the influence of the TMPA rainfall productd on streamflow simulation. Section two and three introduces the study area and hydrologic model. Section four is results and analysis. Conclusions are given in the last section of this paper.

\section{Study area and Data}

The Ganjiang River Basin lies in $113^{\circ} 30^{\prime} \mathrm{E}$ to $116^{\circ} 40^{\prime} \mathrm{E}, 24^{\circ} 29^{\prime} \mathrm{N}$ to $29^{\circ} 11^{\prime} \mathrm{N}$. It is the primary tributary of the Poyang Lake basin, so the Ganjiang River has a great influence on the water level and lake area variation of Poyang Lake. Ganjiang cover area is about $83874 \mathrm{~km}^{2}$.

In this study, the satellite-based rainfall data are daily data from 1 January, 2003 to 31 December, 2009, from four standard TMPA products, real-time products 3B42RT (3B42RTV6 and 3B42RTV7) and bias-adjusted research products 3B42 (3B42V6 and 3B42V7). The observed precipitation comes from the 37 manual rain gauges evenly distributed in Ganjiang basin. These rain gauges are collected from the national standard stations operated by the China Meteorological Administration (CMA).

\section{Hydrological model and Data}

The hydrological model used in this study is the VIC (Variable Infiltration Capacity) model, which is a surface-water and energy-balance model designed for large-scale applications[6]. The VIC model has a long history of use for evaluating the land surface water budget in hydrological studies. The VIC model used in this study has seven major parameters. These parameters was on the contingency table(Table 1).

Table 1. Calibrated Paraments and Calibrated Values in Ganjing River Basin

\begin{tabular}{cclc}
\hline No. & Parameters & \multicolumn{1}{c}{ Definition } & Calibrated value \\
\hline $\mathbf{1}$ & B & Variable infiltration curve parameter (binfilt) & 0.236 \\
\hline $\mathbf{2}$ & Ws & $\begin{array}{l}\text { Fraction of maximum soil moisture where non-linear } \\
\text { baseflow occurs }\end{array}$ & 0.533 \\
\hline $\mathbf{3}$ & Ds & Fraction of Dsmax where non-linear baseflow begins & 0.481 \\
\hline $\mathbf{4}$ & Dsmax & Maximum velocity of baseflow & 13.748 \\
\hline $\mathbf{5}$ & d0 & & 0.300 \\
\hline $\mathbf{6}$ & d1 & Thickness of each soil moisture layer & 2.430 \\
\hline $\mathbf{7}$ & d2 & & 0.533 \\
\hline
\end{tabular}

Relative bias (Bias), correlation coefficient (CC), root mean square error (RMSE) are used to measure differences between the four satellite products. The Bias (\%) was used to measure the agreement between the averaged value of gauge data and observed data. The correlation coefficient (CC) is used to assess the linearity of the correlated datasets. The RMSE also measures the average error magnitude. Besides, the Nash-Sutcliffe (NSCE) index is used to quantify how well the hydrological models are. While value is more close to one, the higher reliability model is. 


\section{Result}

Evaluation of precipitation

Figure 1 shows four TMPA products and the gauge observation spatial distribution of precipitation over Ganjiang basin. It shows that the 3B42RTV6 significantly underestimated the precipitation around the basin while other three TMPA products show better agreement with observed precipitation.
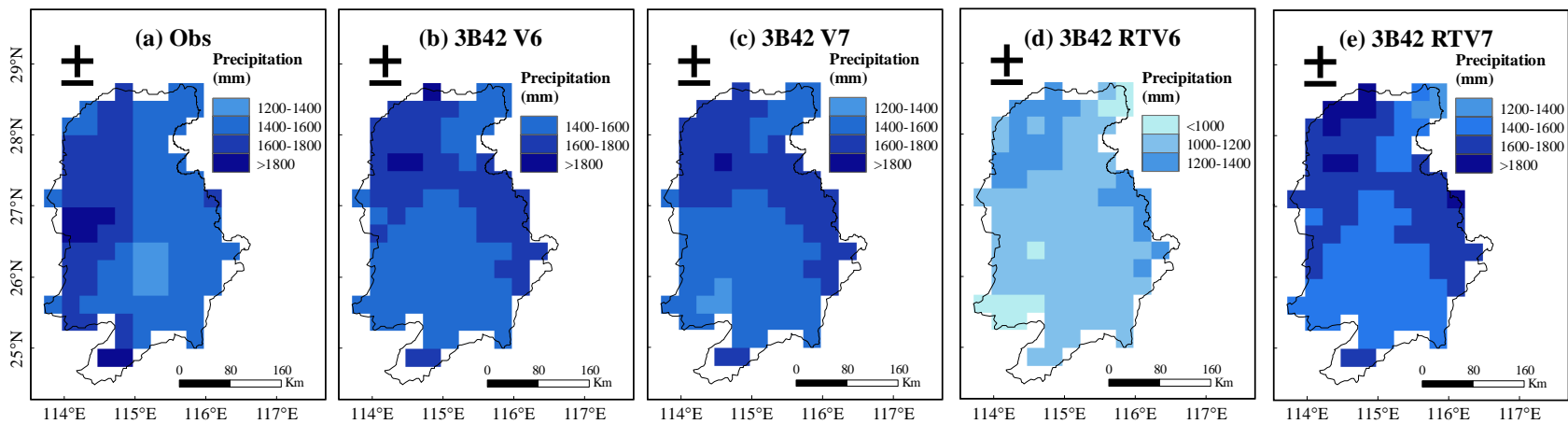

Fig 1. 2003-2009 mean daily precipitation (mm/day) over Ganjiang Basin for (a) Observed precipitation; (b) 3B42V6; (c) 3B42V7; (d) 3B42RTV6 and (e) 3B42RTV7.

Figure 2 shows the quantitative comparison among 3B42RTV6, 3B42RTV7, 3B42V6 and 3B42V7 versus gauge observations in Ganjiang Basin over 7 years at daily scale. We can clearly seen that the 3B42RTV6 is the most underestimated one with poor correlation with the gauge observations and $-24.15 \%$ relative bias. By contrast, 3B42RTV7 shows great improvement with higher Bias, $12.05 \%$. 3B42RTV7 shows similar performance to 3B42V7.
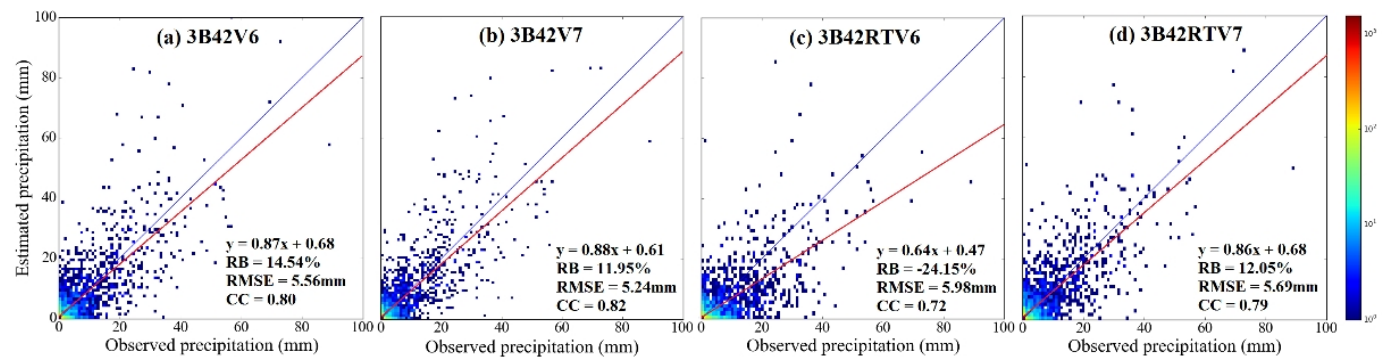

Fig 2. Scatter plots of the grid-based precipitation comparison at 35 selected grid boxes in the ganjiang

Evaluation of Stream Flow basin at daily scale.

In this study, the VIC model is calibrated from 2000 to 2004 and then is used to simulate the streamflow of the basin from 2005 to 2009 . The Bias and NSCE of the calibration period are separately $-14.60 \%$ and 0.829 . So, the VIC model is suitable for this basin.

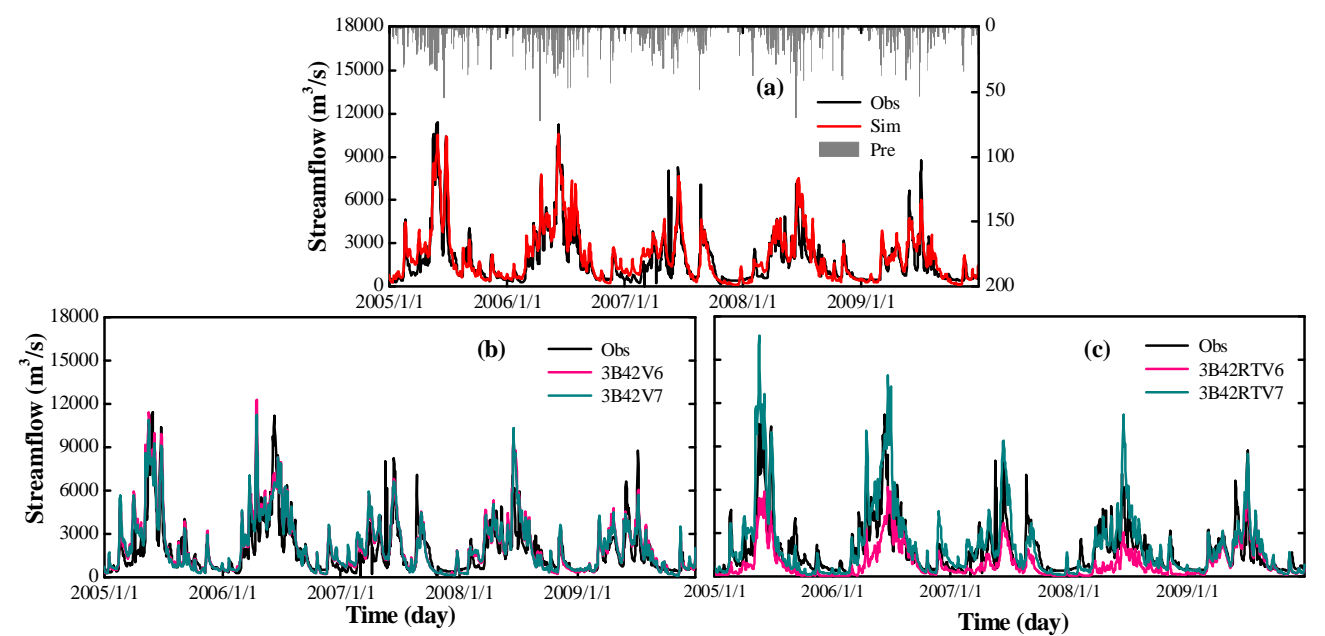

Fig 3. Daily simulations of river discharge with rainfall inputs from (a) gauge; (b) 3B42V6 and 3B42V7 and (c) 3B42RTV6 and 3B42RTV7. 
As shown in Figure 3 and Table 2, streamflow simulated with observed precipitation performance best, with high NSCE (0.86). The TMPA products 3B42V6 and 3B42V7 show very close performance with high CC (0.89) and NSCE (0.72 and 0.75, respectively), which indicating they are suitable for hydrological simulation. In contrast, 3B42RTV6 and 3B42RTV7 are not applicability to water management, they have low NSCE (0.55 and 0.58, respectively).

Table 2. Parameters of the relationship among the observed streamflow, streamflow simulated with TRMM data and streamflow simulated with the observed precipitation from 2005 to 2009.

\begin{tabular}{cccc}
\hline & Bias $(\boldsymbol{\%})$ & CC & NSCE \\
\hline Gauge & 10.29 & 0.93 & 0.86 \\
\hline 3B42V6 & 16.24 & 0.89 & 0.72 \\
\hline 3B42V7 & 14.98 & 0.89 & 0.75 \\
\hline 3B42RTV6 & -34.28 & 0.81 & 0.55 \\
\hline 3B42RTV7 & 15.71 & 0.86 & 0.58 \\
\hline
\end{tabular}

\section{Conclusion}

1) From the comparisons between gauged precipitation and four TMPA rainfall products, results indicate that TRMM3B42 data have fine correlation with gauge precipitation in Ganjiang River Basin.

2) 3B42V6 and 3B42V7 have good hydrologic performance with high NSCE (0.72 and 0.75), high $\mathrm{CC}(0.89)$ at daily scale. 3B42V7 performance better than 3B42V6.

3) Compared with 3B42RTV6, 3B42RTV7 has significantly outperforms in precipitation estimate and hydrologic simulate.

\section{References}

[1] S. Jiang, L. Ren, Y. Hong, B. Yong, X. Yang, F. Yuan, M. Ma, Comprehensive evaluation of multi-satellite precipitation products with a dense rain gauge network and optimally merging their simulated hydrological flows using the Bayesian model averaging method, Journal of Hydrology, 452 (2012) 213-225.

[2] M.R.P. Sapiano, P.A. Arkin, An Intercomparison and Validation of High-Resolution Satellite Precipitation Estimates with 3-Hourly Gauge Data, Journal of Hydrometeorology, 10 (2009) 149-166. [3] S. Chen, Y. Hong, Q. Cao, J.J. Gourley, P.-E. Kirstetter, B. Yong, Y. Tian, Z. Zhang, Y. Shen, J. Hu, J. Hardy, Similarity and difference of the two successive V6 and V7 TRMM multisatellite precipitation analysis performance over China, Journal of Geophysical Research-Atmospheres, 118 (2013) 13060-13074.

[4] B. Yong, B. Chen, J.J. Gourley, L.L. Ren, Y. Hong, X. Chen, W.G. Wang, S. Chen, L.Y. Gong, Intercomparison of the Version-6 and Version-7 TMPA precipitation products over high and low latitudes basins with independent gauge networks: Is the newer version better in both real-time and post-real-time analysis for water resources and hydrologic extremes?, Journal of Hydrology, 508 (2014) 77-87.

[5] Z. Liu, Comparison of versions 6 and 7 3-hourly TRMM multi-satellite precipitation analysis (TMPA) research products, Atmos Res, 163 (2015) 91-101.

[6] S. Prakash, A.K. Mitra, I.M. Momin, D.S. Pai, E.N. Rajagopal, S. Basu, Comparison of TMPA-3B42 Versions 6 and 7 Precipitation Products with Gauge-Based Data over India for the Southwest Monsoon Period, Journal of Hydrometeorology, 16 (2015) 346-362.

[7] Q. Zhao, B. Ye, Y. Ding, S. Zhang, S. Yi, J. Wang, D. Shangguan, C. Zhao, H. Han, Coupling a glacier melt model to the Variable Infiltration Capacity (VIC) model for hydrological modeling in north-western China, Environmental Earth Sciences, 68 (2013) 87-101. 